\title{
Long-Term Potentiation of Thalamocortical Transmission in the Adult Visual Cortex In Vivo
}

\author{
Arnold J. Heynen and Mark F. Bear \\ Department of Neuroscience, Howard Hughes Medical Institute, Brown University, Providence, Rhode Island 02912
}

It has been suggested that NMDA receptor-dependent synaptic strengthening, like that observed after long-term potentiation (LTP), is a mechanism by which experience modifies responses in the neocortex. We report here that patterned (theta burst) stimulation of the dorsal lateral geniculate nucleus reliably induces LTP of field potentials (FPs) evoked in primary visual cortex (Oc1) of adult rats in vivo. The response enhancement is saturable, long-lasting, and dependent on NMDA receptor activation. To determine the laminar locus of these changes, current source density (CSD) analysis was performed on FP profiles obtained before and after LTP induction. LTP was accompanied by an enhancement of synaptic current sinks located in thalamorecipient (layer IV and deep layer III) and supragranular (layers II/III) cell layers. We also examined immunocytochemical labeling for the immediate early gene zif-268 1 hr after induction of LTP. In concert with the laminar changes observed in CSD analyses, we observed a significant increase in the number of zif-268-immunopositive neurons in layers II-IV that occurred over a wide extent of Oc1. Last, we investigated the functional consequences of LTP induction by monitoring changes in visually evoked potentials. After LTP, we observed that the cortical response to a full-field flash was significantly enhanced and that responses to grating stimuli were increased across a range of spatial frequencies. These findings are consistent with growing evidence that primary sensory cortex remains plastic into adulthood, and they show that the mechanisms of LTP can contribute to this plasticity.

Key words: critical period; visual cortex; synaptic plasticity; LTP; zif-268; dLGN
The responses of neocortical neurons can be persistently modified by alterations in sensory experience. Such modifications reflect changes in synaptic transmission that shape cortical circuits and store information. In primary sensory neocortex, it is well documented that such experience-dependent modifications occur most readily during critical periods of early postnatal development. However, increasing evidence suggests that similar changes can occur in adults under the appropriate circumstances. It is also apparent that regardless of age, experience-dependent cortical plasticity can have a large functional impact on sensory performance (Weinberger, 1995; Buonomano and Merzenich, 1998). Thus, a question of central importance in neurobiology concerns the mechanisms by which experience produces lasting changes in synaptic strength in neocortex.

A fruitful approach has been to study synaptic modifications in acutely prepared cortical slices. Such experiments have revealed widespread expression of NMDA receptor-dependent long-term potentiation (LTP) and long-term depression (LTD) at synapses in many cortical regions in a large number of species, including humans (Bear, 1996; Chen et al., 1996). In visual cortex, it has been suggested that the mechanisms of LTP contribute to experience-dependent acquisition of visual responsiveness during the critical period (Bear et al., 1987; Frégnac and Shulz, 1994; Singer, 1995). Consistent with this notion, LTP measured in layer III is readily elicited by stimulation of the white matter in neo-

Received Aug. 7, 2001; revised Sept. 18, 2001; accepted Oct. 3, 2001.

This work was partly supported by grants from the National Institutes of Health and the Human Frontiers Science Program. We thank Erik Sklar, Suzanne Meagher, and Anna Shusterman for assistance.

Correspondence should be addressed to Mark Bear, Howard Hughes Medical Institute and Department of Neuroscience, Brown University, Providence, RI 02912. E-mail: Mark_Bear@Brown.edu.

Copyright (C) 2001 Society for Neuroscience $\quad 0270-6474 / 01 / 219801-13 \$ 15.00 / 0$ nates, and, like naturally occurring plasticity, this capability declines with age (Kato et al., 1991; Kirkwood et al., 1995).

Brain slice experiments are advantageous for mechanistic investigations of synaptic plasticity, and there has been tremendous progress in understanding the molecular basis of NMDA receptor-dependent LTP (Malenka and Nicoll, 1999). However, the significant challenge remains to relate the mechanisms of LTP to naturally occurring plasticity. One important step to bring these forms of synaptic plasticity into closer correspondence is to understand the properties and functional consequences of LTP in the intact brain. However, relatively little is known about NMDA receptor-dependent LTP in the neocortex in vivo, particularly in the visual system. Synaptic potentiation has been induced in kitten visual cortex by prolonged low-frequency stimulation of the optic nerves or dorsal lateral geniculate nucleus (dLGN) (Komatsu et al., 1988; Tamura et al., 1992); however, this effect does not require NMDA receptor activation (Komatsu et al., 1991). Therefore, we felt it was important to investigate whether, using conditioning procedures previously shown to elicit NMDA receptor-dependent LTP in vitro, a similar form of synaptic strengthening also occurs in the visual cortex in vivo.

Here we report that NMDA receptor-dependent LTP is readily induced in primary visual cortex of adult rats in vivo after application of theta-burst stimulation to the dLGN. Current-source density analysis, as well as the expression patterns of the immediate early gene zif-268, suggest that thalamocortical and intracortical synapses are potentiated. A functional consequence of LTP is an enhanced cortical response to visual stimuli. These results suggest that the developmental decline in LTP previously observed in slices is relative, not absolute. The mechanisms of NMDA receptor-dependent LTP are available to support experience-dependent cortical modifications well into adulthood. 


\section{MATERIALS AND METHODS}

Animals. Adult [greater than postnatal day 75 (P75)] male Long-Evans black-hooded rats (Charles River, Cambridge, MA) were used. Animals were group-housed, with food and water available ad libitum, and they were maintained on a $12 \mathrm{hr}$ light/dark cycle.

Anesthesia and electrophysiology. Rats were anesthetized initially with an intraperitoneal injection of Nembutal $(65 \mathrm{mg} / \mathrm{kg})$ supplemented with Isoflurene $(2.0-3.0 \%$ in $100 \%$ oxygen) delivered through a nose cone. A tracheotomy was performed, and an endotracheal tube (14 gauge catheter; Abbott Labs, Chicago, IL) was inserted and secured with 3-0 nylon thread. Animals were then positioned in a stereotaxic frame and artificially ventilated (Hallowell EMC, Pittsfield, MA) using 100\% oxygen (40-70 breaths/min; $0.21 / \mathrm{min}$ ). Pulse oximetry performed on a subset of animals demonstrated that blood $\mathrm{O}_{2}$ levels were 93-98\% throughout experimentation. A surgical plane of anesthesia was maintained throughout the remainder of experimentation by continuous administration of Nembutal via an intraperitoneal catheter $(6-10 \mathrm{mg} / \mathrm{hr})$. To ensure preparation stability, the cortical electroencephalogram was continually monitored. The animal's temperature was measured with a rectal thermoprobe and maintained at $37 \pm 0.5^{\circ} \mathrm{C}$ with a water heating pad (Gaymar Industries, Orchard Park, NY). Throughout experimentation, with the exception of when visual stimuli were presented, both eyes were covered with black opaque camera tape.

Care was taken when exposing the visual cortex. A dental drill was used to make a hole $(\sim 3.0 \times 3.0 \mathrm{~mm})$ in the skull overlying the primary visual cortex (Oc1). The dura was kept intact to minimize damage to the cortex, and the exposed region was covered with either warm saline or silicone grease to prevent drying. Monopolar recordings from Oc1 (tungsten microelectrode; $<1.0 \Omega$ tip resistance; FHC, Bowdingham, ME) were made relative to a ground screw inserted into the bone overlying the cerebellum. Recording electrodes were positioned on the dural surface, except when electrode tracking experiments were performed; in these instances a small incision was made in the dura using a 30 gauge needle to allow entry of a roving microelectrode. A burr hole was also drilled in the skull (3.8 $\mathrm{mm}$ posterior to bregma, 3.3-3.4 mm lateral to midline) to allow a concentric bipolar stimulating electrode (FHC; $200 \mu \mathrm{m}$ diameter) to be positioned in the dLGN ipsilateral to the hemisphere in which Oc1 recordings were obtained. To accurately position the tip of the stimulating electrode in the dLGN, visually driven multiunit activity was monitored as this electrode was slowly tracked down through neocortex and overlying hippocampus. The final depth of the stimulating electrode tip was typically within $100-200 \mu \mathrm{m}$ of the point at which visually responsive neurons were first encountered.

Final positions of the stimulating and recording electrodes were then determined by maximizing the amplitude of the field potential (FP) recorded in Oc1 in response to pulsed electrical stimulation of the dLGN. Maximum amplitude FPs were obtained with the recording electrode positioned $>7.0 \mathrm{~mm}$ posterior to bregma and $3.0-4.0 \mathrm{~mm}$ lateral to the midline, corresponding to primary visual cortex in the rat (Zilles, 1985). Histological analysis demonstrated that the stimulating electrode tip was typically positioned within the first $200 \mu \mathrm{m}$ of the dorsal surface of the dLGN (Fig. 1b), near the anterior pole where optic radiation fibers are bundled in close proximity (Hughes, 1977; Molnar et al., 1998).

Field potentials were elicited using stimuli of $0.2 \mathrm{msec}$ duration at a stimulus intensity of $0.3-1.1 \mathrm{~mA}$. Evoked responses were amplified $(1000 \times)$ and filtered at 0.1 and $3.0 \mathrm{kHz}$ (half-amplitude), digitized at 160 $\mathrm{kHz}$, and stored and analyzed using Experimenter's Workbench (DataWave Technologies, Longmont, CO). Before the beginning of each experiment a full input-output series was performed, and a stimulation intensity yielding a FP amplitude $50-60 \%$ of maximum was used for the remainder of the experiment. Baseline responses were collected every 30 sec for 30-60 min before application of theta-burst stimulation (TBS). TBS consisted of 10 bursts at $5 \mathrm{~Hz}$, with each burst containing 5 pulses at $100 \mathrm{~Hz}$, given four times with a $10 \mathrm{sec}$ interval between each train of 10 bursts.

In experiments designed to determine whether LTP of the thalamocortical pathway is dependent on NMDA receptor activation, recording and stimulating electrodes were placed bilaterally in each hemisphere, and animals received an intraperitoneal injection of the competitive NMDA receptor antagonist ( \pm )-3-(2-carboxypiperazin-4-yl)-propyl-Lphosphonic acid (CPP; $10 \mathrm{mg} / \mathrm{kg}$; Research Biochemicals, Natick, MA). Electrophysiological data are expressed as a percentage of the mean response magnitude recorded during the baseline recording period.

Current source density analysis. Current source density (CSD) analysis was performed to determine the spatiotemporal pattern of current sinks and sources evoked in Oc1 by photic stimulation of the retinas and electrical stimulation of the dLGN. In these experiments, in addition to a reference recording electrode positioned at dural surface, a second roving electrode was tracked down through Oc1 in $100 \mu \mathrm{m}$ steps. At each recording depth, 10 stimuli were delivered, either in the form of pulsed stimulation to the dLGN or flash stimulation (full-field stroboscopic stimulation of $10 \mu \mathrm{sec}$ duration, delivered via a Braun photoflash positioned $40 \mathrm{~cm}$ from the eyes). Roving electrode penetrations were performed perpendicular to the cortical surface to a depth of $2.2-2.5 \mathrm{~mm}$ from dural surface. In cases in which LTP was to be induced, TBS was then applied to the dLGN and after $\sim 15 \mathrm{~min}$ the roving recording electrode was withdrawn in $100 \mu \mathrm{m}$ steps, and the stimulating and recording procedure was repeated. Control experiments in which these tracking procedures were performed in the absence of TBS application demonstrated that dorsoventral tracking of the roving electrode had no observable effect on the magnitude or location of current sinks and sources. At the completion of each recording session small electrolytic lesions were made at various depths along the recording track to allow for anatomical verification of the path of the roving electrode. Animals were then given an overdose of Nembutal and transcardially perfused with saline $(0.9 \%)$, followed by formalin $(10 \%)$. Brains were immersed in a sugar formalin solution (30\%) until sectioning. Serial frozen sections (40 $\mu \mathrm{m})$ were cut in the coronal plane, mounted on gelatin-coated slides, and stained with cresyl violet.

From the field potentials collected, the corresponding one-dimensional (depth) CSD profile was constructed according to the method described by Mitzdorf (1985), using a spatial differentiation grid of $200 \mu \mathrm{m}$. This analysis was performed assuming that the tissue conductivity through Oc1 was homogenous and that current flows normal to the cortical surface. A full account of the theoretical basis of CSD analysis has previously been presented (Freeman and Nicholson, 1975; Mitzdorf, 1985).

For the two most superficial CSD traces, we used the extrapolation method (Vaknin et al., 1988), in which the dural recording site provided the necessary data. Summation of all CSD traces across depths gave values approximating zero, indicating that current sinks and sources were positioned within, and restricted to, the tissue sampled. Color image plots were generated from the CSD profiles to facilitate visualization of the spatiotemporal pattern of cortical current sources and sinks. Image plots were generated by linear interpolation along the depth axis (Aizenman et al., 1996). The exact cortical layers corresponding to the vertical scale of the CSD and contour profiles were reconstructed with the aid of the histologically verified recording electrode tracks and marker lesions.

Zif-268 immunohistochemistry. In experiments in which immunohistochemistry for the immediate early gene (IEG) product zif-268 was performed, animals were prepared with recording and stimulating electrodes placed bilaterally in each hemisphere. After a $1 \mathrm{hr}$ baseline period in which alternating pulses were applied to the dLGN of each hemisphere, TBS was applied to the dLGN of one hemisphere after which alternating baseline stimulation was resumed for an additional $1 \mathrm{hr}$. Animals were then perfused transcardially for 10-15 min with heparinized saline $(20 \mathrm{U} / \mathrm{ml}$ heparin in $0.9 \% \mathrm{NaCl})$ followed by a $20-30 \mathrm{~min}$ perfusion of $4 \%$ paraformaldehyde containing $0.02 \%$ picric acid. After perfusion, brains were removed and immersed overnight in fixative solution. Coronal sections $(50 \mu \mathrm{m})$ from visual cortex were cut on a vibrating microtome and collected in $0.1 \mathrm{M}$ PBS. Antibody labeling was performed on free-floating sections using the avidin-biotin complex method (Pierce, Rockford, IL). Before labeling, sections were pretreated with hydrogen peroxide ( $0.3 \%$ in PBS, $30 \mathrm{~min})$ to inhibit endogenous peroxidase activity; Triton $\mathrm{X}-100(0.3 \%$ in PBS, $30 \mathrm{~min})$ to improve antibody penetration; and normal goat serum (1.5\% in PBS, $20 \mathrm{~min})$ to block nonspecific antibody binding. Sections were rinsed in PBS (three to five washes, 5 min each) between each preincubation step. Sections were then incubated overnight in primary antibody against zif-268 (Santa Cruz Biotechnology, Santa Cruz, CA; 1:1000 in PBS with 1.5\% normal goat serum, $4^{\circ} \mathrm{C}$ ). Sections were next rinsed in PBS (three washes, 5 min each) and incubated in secondary antibody (Pierce; biotinylated goat antirabbit IgG, 1:200, $30 \mathrm{~min}$ ), rinsed (three washes, $5 \mathrm{~min}$ ), incubated in avidin-biotin reagent (Pierce; $30 \mathrm{~min}$ ), and rinsed once again (three washes, 5 min each). Sections were briefly immersed in Triton X-100 $(0.3 \%$ in PBS) followed immediately by the DAB reaction (diaminobenzidine $0.1 \%$ with $0.01 \%$ hydrogen peroxide, $5-10 \mathrm{~min}$ ). The sections were then rinsed in distilled water and mounted on gelatin-coated slides. Sections were subsequently counterstained by immersing in ethidium bromide (Sigma, St. Louis, MO; 0.0001\% in PBS, pH 7.2, 2 min), 


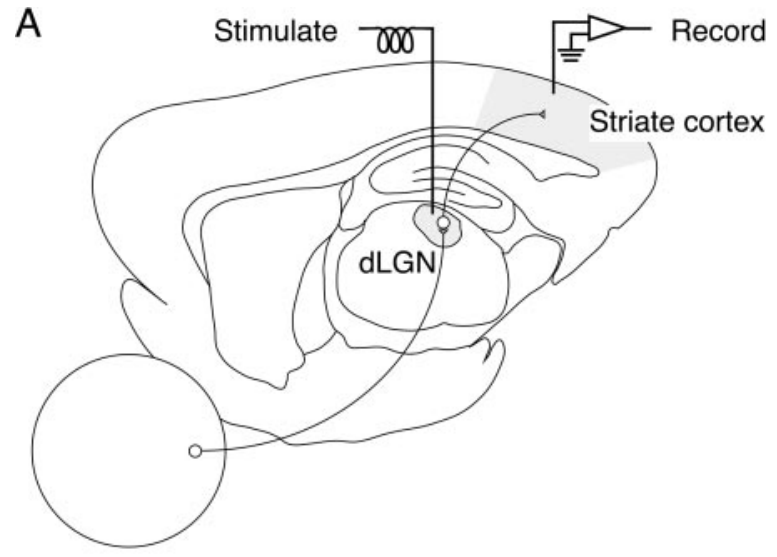

B

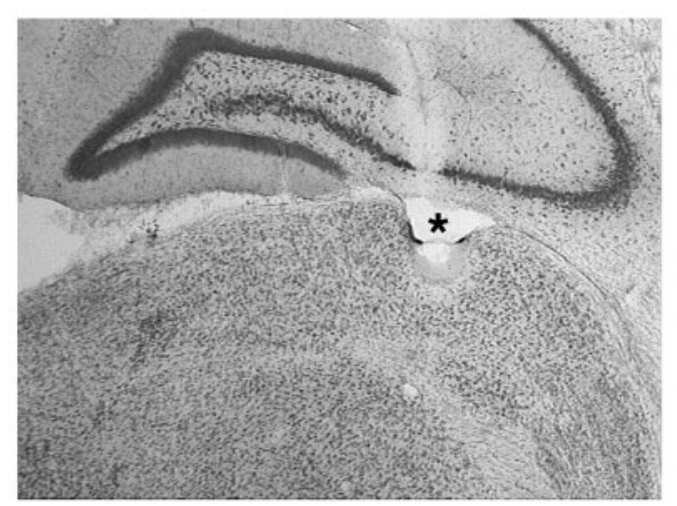

C
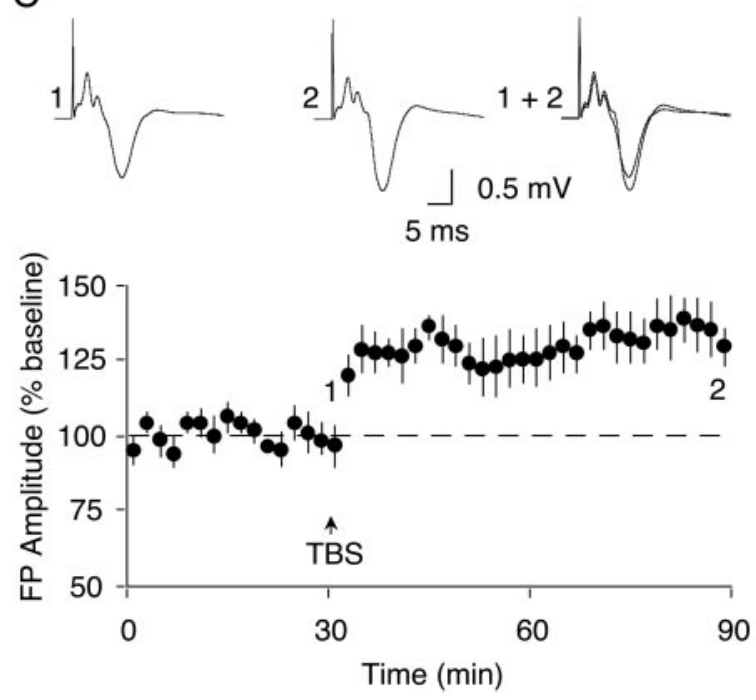

Figure 1. Application of TBS to the dLGN elicits LTP in the adult Oc1 in vivo. $A$, Schematic diagram illustrating position of monopolar recording electrode in Oc1 and concentric bipolar stimulating electrode in the dLGN. B, Cresyl violet-stained coronal section showing electrolytic lesion (*) in the dLGN, indicating position of stimulating electrode tip. Lesion was made at end of recording session by applying $1.0 \mathrm{~mA}$ for $5.0 \mathrm{sec}$ through electrode. $C$, TBS applied to the dLGN elicits LTP of FPs in Oc1. After a $30 \mathrm{~min}$ baseline recording period, application of TBS (indicated by arrow) to the dLGN produces stable LTP of the negative-going component of FPs recorded in Oc1. Traces illustrate increase in FP amplitude observed 60 min after TBS in one experiment. Traces here and in subsequent figures are taken from one representative animal in each group and are averages of 10 consecutive FPs taken at times indicated by numbers. followed by PBS (1 min) and distilled $\mathrm{H}_{2} \mathrm{O}(15 \mathrm{sec})$. Slides were allowed to fully air dry and then coverslipped with glycerol (1\% in PBS). Counterstaining in this manner has been shown to preferentially stain nuclei and cytosol without masking DAB-positive nuclei (Schmued et al., 1982).

To confirm the specificity of antibody labeling, three experimental controls were performed: (1) In every experiment, sections were processed in a manner identical to that described above with the exception of the primary antibody step. This procedure, which is a control for nonspecific staining by the secondary antibody, produced no staining. (2) Tissue sections were treated with primary antibody which had been preadsorbed with zif-268 peptide (Santa Cruz Biotechnology). These sections were also devoid of staining. (3) Some sections were treated with primary antibody that had been preadsorbed with c-Fos peptide (Santa Cruz Biotechnology). These sections exhibited normal nuclear staining.

Quantification of immunostaining. To determine the percentage of neurons positively stained for zif-268, cell counts were performed on layers II/III, IV, and VI of each hemisphere for each animal. Layers I and $\mathrm{V}$ were excluded from analysis because neurons in these layers typically exhibit very little zif-268 staining. To perform meaningful cell counts and to account for differential shrinkage of the tissue, it is necessary to quantify the number of zif-268-stained nuclei in relation to the total number of neurons in the image. Therefore, the same region of the tissue section was imaged using both bright-field optics to determine the number of zif-268-positive neurons and rhodamine epifluorescence optics to allow for the quantification of the total number of neurons within the image. Images were obtained using a Photometrics CCD camera mounted on a Nikon Eclipse 800 microscope running IPLab Spectrum software. Sections were chosen that were approximately midway between the anterior and posterior limits of Oc1. Within each cell layer of interest, cells were counted manually by a researcher blind to experimental condition using NIH Image software. Zif-268 immunoreactivity was expressed as the percentage of total neurons in a particular layer that stained positively for zif-268. The number of zif-268-positive neurons in Oc1 of the hemisphere expressing LTP was compared with the same animal control Oc1 (baseline stimulation only) using paired $t$ tests.

Visually evoked potential recordings. In experiments designed to determine the effect LTP induction has on the cortical response to patterned visual stimulation of the retinas, animals were prepared as previously described, with the exception that urethane anesthesia was used (2 $\mathrm{gm} / \mathrm{kg}$ ). Recording and stimulating electrodes were positioned bilaterally in each hemisphere. Baseline FPs in response to dLGN stimulation were monitored for 15-30 min followed by a period in which transient visually evoked potentials (VEPs) in response to stimuli of varying spatial frequencies were collected. dLGN-evoked responses were once again measured (15-45 $\mathrm{min})$ followed by application of TBS to the dLGN of one hemisphere. After TBS, dLGN-evoked responses were monitored to ensure induction of LTP (>30 min), at which time a final VEP series was collected.

Visual stimuli consisted of horizontally oriented sinusoidal gratings of varying spatial frequencies presented on a computer monitor (Brainwave, SVGA) placed $15 \mathrm{~cm}$ from the eyes, in a darkened room. VEPs were amplified $(1000 \times)$, filtered $(0.1$ and $1.0 \mathrm{kHz})$, digitized at $10 \mathrm{kHz}$, and averaged ( $>100$ events per spatial frequency) in synchrony with stimulus contrast reversal using an IBM-compatible computer running Experimenter's Workbench (DataWave Systems). Transient VEPs in response to abrupt contrast reversing stimuli $(1 \mathrm{~Hz})$ were analyzed by measuring the amplitude of the positive peak of the major response component. VEPs in response to a stimulus of $0 \%$ contrast were also recorded as an estimate of noise. Only those spatial frequencies in which a VEP was clearly discernible in both hemispheres before and after application of TBS were considered for analysis. Under the anesthetic conditions used, reliably quantifiable VEPs were observed at spatial frequencies from 0.05 to 0.5 cycles $/{ }^{\circ}$. For presentation, data from each hemisphere were normalized to the VEP amplitude obtained using a $0.05 \mathrm{cycle}^{\circ}$ stimulus during the pre-TBS recording period.

\section{RESULTS}

\section{Characteristics of LTP evoked with tetanic stimulation of the thalamocortical pathway in vivo}

To investigate the possibility that LTP can be elicited in the adult visual cortex in vivo, animals were prepared with a recording electrode positioned at the surface of Oc1 and a concentric bipolar stimulating electrode in the ipsilateral dLGN (Fig. 1A,B). Single-pulse stimulation applied to the dLGN evoked a primarily 
negative-going FP in Oc1 with a latency to peak of $\sim 10 \mathrm{msec}$. After a stable $30 \mathrm{~min}$ baseline period, TBS was applied to the dLGN. Similar to what has been described in slice studies of neocortical LTP (Kirkwood and Bear, 1994), the FP amplitude increased gradually over the first 5-10 min after tetanization, before reaching a stable potentiated level. The increase in FP amplitude measured $60 \mathrm{~min}$ after TBS was $135.3 \pm 5.3 \%$ of baseline (Fig. $1 C)(n=10 ; p<0.001)$.

An important characteristic of bidirectionally modifiable synapses throughout the cerebral cortex is they possess a limit to the amount of potentiation and depression that can be induced (Rioult-Pedotti et al., 2000). This limit can be probed by repeated application of conditioning stimulation. Therefore, we attempted to saturate LTP by applying repeated episodes of TBS at $1 \mathrm{hr}$ intervals to the dLGN (Fig. $2 A$ ). Application of three episodes of TBS resulted in a significant potentiation of the FP amplitude compared with baseline (ANOVA; $F_{(3,16)}=6.68 ; p<0.005$ ). The level of potentiation achieved after the first episode of TBS (127.3 $\pm 9.3 \%$ of baseline) appears to be relatively saturating because only modest changes in FP amplitude were observed after the second $(137.6 \pm 7.2 \%)$ and third $(130.0 \pm 6.4 \%)$ tetanization episodes (Student-Newman-Keuls; $p>0.05$ ).

A characteristic of LTP that makes it an attractive candidate mechanism for long-term information storage is the stability of the change over time. In our experiments we observed that LTP of the FP amplitude in visual cortex was also very stable. Figure $2 B$ presents data from an experiment in which the potentiation was followed as long as the preparation was viable. LTP induced with three episodes of TBS lasted for $>10 \mathrm{hr}$ without any sign of decrement.

In visual cortical slices, LTP elicited by application of TBS requires activation of NMDA receptors (Kirkwood et al., 1993; Kirkwood and Bear, 1994). Therefore, we next investigated whether induction of LTP in vivo involves similar mechanisms. In these experiments, animals $(n=5)$ were prepared with stimulating and recording electrodes positioned in the dLGN and Oc1 of each hemisphere. Baseline responses were collected for a $1 \mathrm{hr}$ period by alternately applying stimulation to each dLGN. TBS was then applied to the dLGN of one hemisphere, and then each animal was injected with the competitive NMDA receptor antagonist ( \pm )-3-(2-carboxypiperazin-4-yl)-propyl-1-phosphonic acid (CPP; $10 \mathrm{mg} / \mathrm{kg}$, i.p.). One hour after CPP treatment, a time when CPP has been shown to be maximally effective at blocking NMDA receptor-dependent LTP in vivo (Abraham and Mason, 1988; Heynen et al., 1996), TBS was applied to the dLGN of the previously untetanized hemisphere. As is shown in Figure $2 C$, LTP of the FP amplitude $(129.8 \pm 14.7 \%$ of baseline; $p<0.05)$ was induced in Oc1 of the hemisphere receiving TBS immediately before CPP administration. Moreover, potentiation of the FP amplitude was maintained in the presence of the NMDA receptor antagonist. Conversely, in these same animals, LTP was not observed in Oc1 when TBS was applied $1 \mathrm{hr}$ after CPP administration $(96.8 \pm 9.8 \%$ of baseline; $p>0.05)$. These findings demonstrate that induction of stable LTP in Oc1 in vivo requires NMDA receptor activation. Once induced, however, maintenance of LTP is NMDA receptor independent.

\section{Current source density analysis of cortical responses to dLGN and retinal stimulation}

The preceding experiments demonstrate LTP of a component of the dLGN-evoked FP in visual cortex. To understand the meaning of a change in this surface-recorded FP, we performed a CSD
A
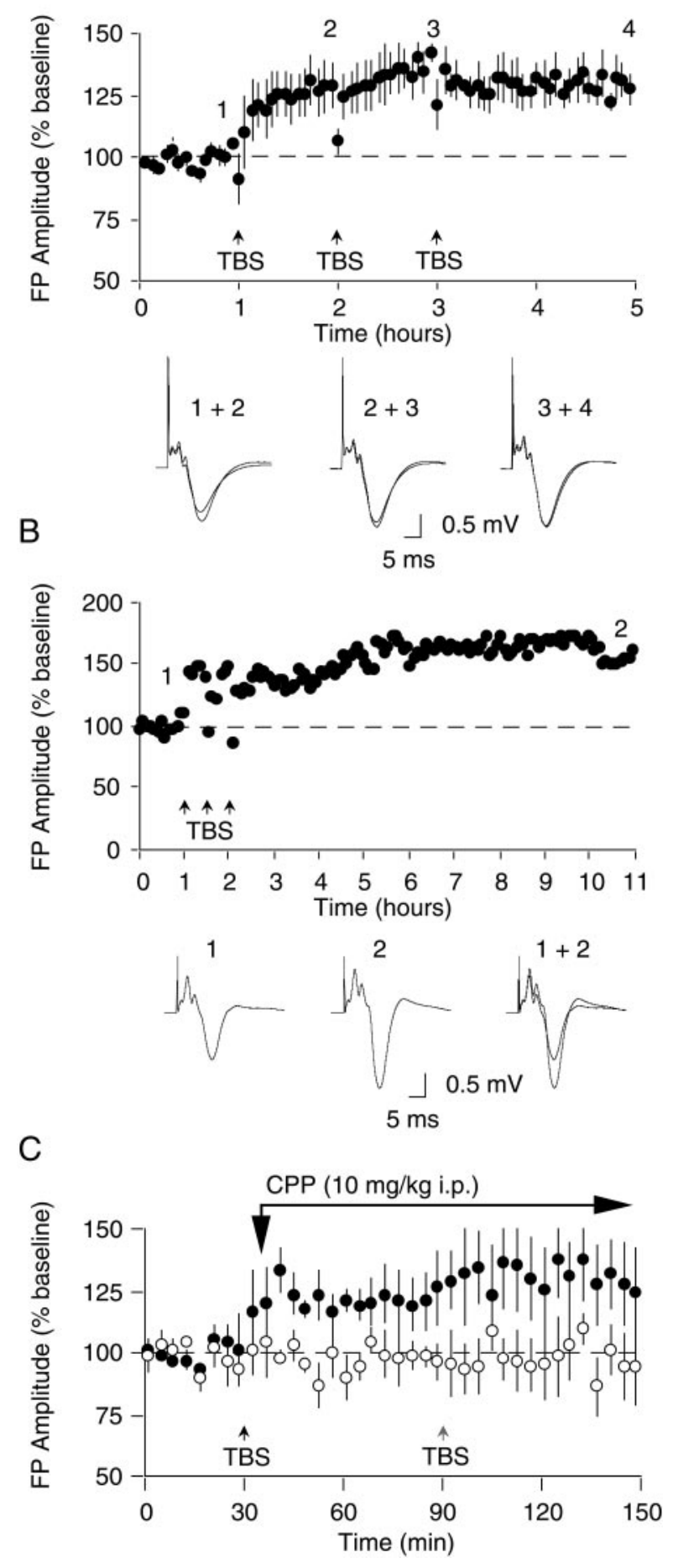

Figure 2. TBS-induced LTP in Oc1 in vivo is saturable, long-lasting, and NMDA receptor-dependent. $A$, LTP in Oc1 in vivo is saturable. Repeated application of TBS at $1 \mathrm{hr}$ intervals saturates LTP and produces potentiation that remains stable for $2 \mathrm{hr}$ after the last tetanization. B, TBSinduced LTP in Oc1 is long-lasting. In this example, three episodes of TBS produced stable LTP that lasted for $>10.0 \mathrm{hr}$ after initial tetanization. $C$, TBS-induced LTP in Oc1 is prevented by the NMDA receptor antagonist CPP. LTP is reliably evoked in Oc1 when TBS is applied to the dLGN before CPP administration (closed circles), whereas in these same animals LTP is blocked in Oc1 of the contralateral hemisphere when TBS is applied $1 \mathrm{hr}$ after CPP administration (open circles). Black arrow indicates time of first TBS application and CPP administration $(10 \mathrm{mg} / \mathrm{kg}$, i.p.); gray arrow indicates TBS application $1 \mathrm{hr}$ after CPP administration. 
analysis. CSD analysis enables one to determine the laminar location, direction (source vs sink), magnitude, and temporal order of the transmembrane currents that are responsible for generating the local FPs. It was of particular interest to compare the spatiotemporal pattern of cortical activation by dLGN stimulation with that evoked by photic stimulation of the retinas, and to assess the consequences of inducing LTP.

A recording electrode was tracked ventrally through Oc1 in 100 $\mu \mathrm{m}$ steps from the dural surface to well below white matter $(\geq 2$ $\mathrm{mm}$ ventral). After each $100 \mu \mathrm{m}$ advancement of the recording electrode, 10 FPs in response to either single pulse stimulation of the dLGN or photic stimulation of the retinas were collected, averaged, and subjected to CSD analysis. A representative example of the cortical FP depth profile in response to dLGN stimulation is presented in the left column of Figure $3 A$. The FPs recorded through the depth of Oc1 were consistently observed as primarily negative-going potentials, having a maximum negativity and shortest latency at a depth corresponding to layer IV and deep layer III ( $\sim 600-800 \mu \mathrm{m}$ ventral to the dural surface). The resultant CSD profile and color image plot for the FP data are presented in the middle and right columns, respectively. The shortest latency ( $\sim 2-5 \mathrm{msec})$ current sinks were observed in layer IV and lower (deep) layer III, with corresponding sources located in adjacent extragranular layers. These initial current sinks were followed by sinks in supragranular (depth: $\sim 200-500 \mu \mathrm{m}$ ) and infragranular (depth: $\sim 800-1100 \mu \mathrm{m}$ ) layers, with the latency of these sinks increasing with distance from layer IV/deep layer III. Although slight variations in the magnitude and latency of current sinks were observed between preparations $(n=4)$, the laminar pattern and temporal order of transmembrane currents were consistent across animals.

Figure $3 B$ presents a similar analysis of Oc1 activation in an animal in which FPs were evoked by flash stimulation of the retinas. The FPs and resulting CSD profiles are consistent with previous reports (Mitzdorf, 1985; Vaknin et al., 1988; Brankack et al., 1990; Ferster, 1990; Kenan-Vaknin and Teyler, 1994). It is obvious from inspection of Figure 3 that the laminar profile of current sinks and sources observed after pulsed electrical stimulation of the dLGN is qualitatively very similar to that observed in response to photic stimulation of the retinas. Both types of stimulation result in an excitatory "feedforward" pattern of activation in Oc1, with the first prominent current sinks occurring in geniculo-recipient layer IV and deep III, followed by longer latency sinks in the extragranular layers. It is well established that the short-latency current sinks reflect monosynaptic geniculocortical transmission and that the later sinks arise from disynaptic and polysynaptic activation of intracortical connections outside of layer IV (Mitzdorf, 1985; Vaknin et al., 1988; Brankack et al., 1990; Kenan-Vaknin and Teyler, 1994).

The similarity of these patterns of activation is significant. Unlike synaptic activation of the dLGN by retinal stimulation, direct electrical activation of the dLGN can, in principle, evoke antidromic action potentials in corticogeniculate axons arising in layer VI. However, as observed in similar studies (Mitzdorf and Singer, 1978; Mitzdorf, 1985), CSD analysis failed to reveal synchronous antidromic action currents after dLGN stimulation. This finding seems to be accounted for mainly by the fact that, because of their fine caliber and weak mylenation, the threshold for activation of corticothalamic axons is higher than that for thalamocortical fibers (Tsumoto and Suda, 1980; Swadlow and Weyand, 1981; Ferster and Lindstrom, 1983; Bourassa and Deschenes, 1995). In any case, it is apparent that the FPs generated by dLGN stimulation primarily reflect excitatory synaptic currents generated in visual cortex by activation of the thalamocortical projection.

It is also noteworthy, however, that although flash stimulation of the retinas is effective in eliciting reliable short latency responses in Oc1, electrical stimulation of the dLGN appears to be more efficacious in recruiting the thalamocortical pathway. Comparison of the CSD profiles presented in Figure 3 reveals that pulsed stimulation of the dLGN results in transmembrane currents in Oc1 which are an order of magnitude larger than those observed after photic stimulation.

\section{Current source density analysis of LTP}

We next performed CSD analyses on FP profiles obtained before and after application of TBS to determine the laminar profile of potentiated synaptic transmission. In this series of experiments, baseline FPs in response to dLGN stimulation were first collected as a roving electrode was advanced ventrally through the cortex in $100 \mu \mathrm{m}$ steps. TBS was then applied, and after a delay of $15 \mathrm{~min}$, FPs were again collected at $100 \mu \mathrm{m}$ intervals as the electrode was withdrawn. Control experiments, in which this same tracking procedure was performed in the absence of TBS, demonstrated that advancement and withdrawal of the roving electrode in this manner had no observable effect on the spatiotemporal profile of current sinks and sources ( $n=4$; data not shown).

TBS induced a significant increase in the amplitude of the negative-going component of the FP recorded at the cortical surface $(125.1 \pm 10.6 \%$ of pretetanus value; $p<0.05)$. CSD analysis in all cases $(n=7)$ confirmed that this change primarily reflects LTP of current sinks in the superficial cortical layers (Table 1). Quite unexpectedly, however, in a number of animals we also observed potentiation in the amplitude of current sinks located in thalamorecipient layers IV and deep III. Figure 4 presents the FP and CSD profiles obtained before and after LTP induction in one such case. In this example, the amplitude of the negative-going FP is clearly potentiated at depths corresponding to layers IV and deep III. CSD analysis confirmed that the magnitude of current sinks in these layers was markedly increased $(>250 \%)$, and that there was a contemporaneous increase in the current sources in superficial layer II-III, and in superficial layer V. At longer latencies, potentiated sinks also appear in layers II and superficial III. Note, in addition, the emergence of a long duration current sink in layer $\mathrm{V}$ after TBS. As layer $\mathrm{V}$ is a major target of layer II/III neurons (Parnavelas et al., 1977; Burkhalter, 1989; Kenan-Vaknin et al., 1992), the emergence of this sink likely reflects the recruitment of a larger population of layer II/III neurons after LTP (Aizenman et al., 1996).

The CSD profiles before and after TBS are overlaid for six additional experiments in Figure 5, showing the full range of results. All cases show clear evidence of potentiation of synaptic current sinks in layers II and III; the CSD plots in the left column $(A-C)$ show, in addition, potentiation of sinks in layer IV. It is interesting to note that there appears to be a reciprocal relationship between the CSD changes in the most superficial layers and those in the middle layers. When the sinks in the middle layers show clear potentiation, as in Figure $5 A-C$, the concomitant increase in the superficial current sources obscures and increases the latency of the sinks at those depths. Conversely, when the most superficial sinks show clear potentiation, as in Figure $5 D-F$, there is a tendency for the middle layer sinks to diminish and, in some cases (Fig. 5E), be replaced by a current source. Because CSD analysis can only reveal net currents, potentiated inward 
A. LGN stimulation

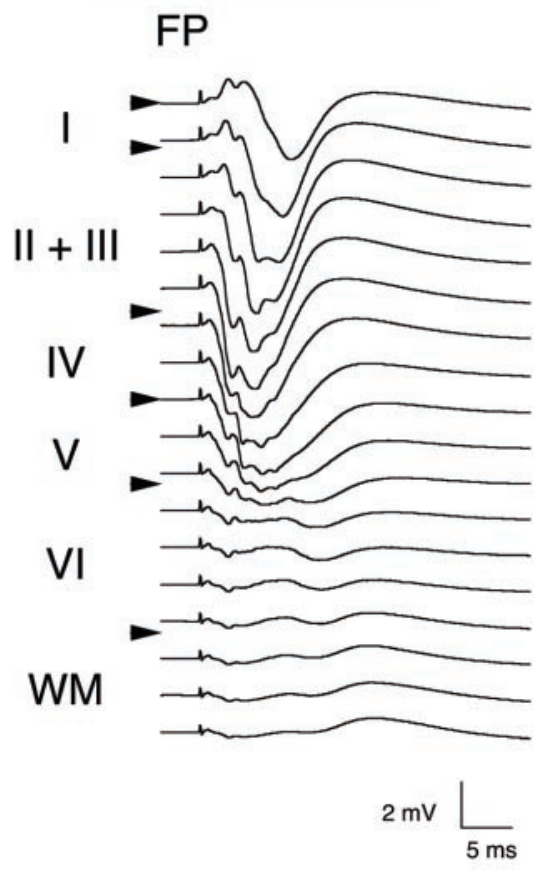

B. Photic stimulation

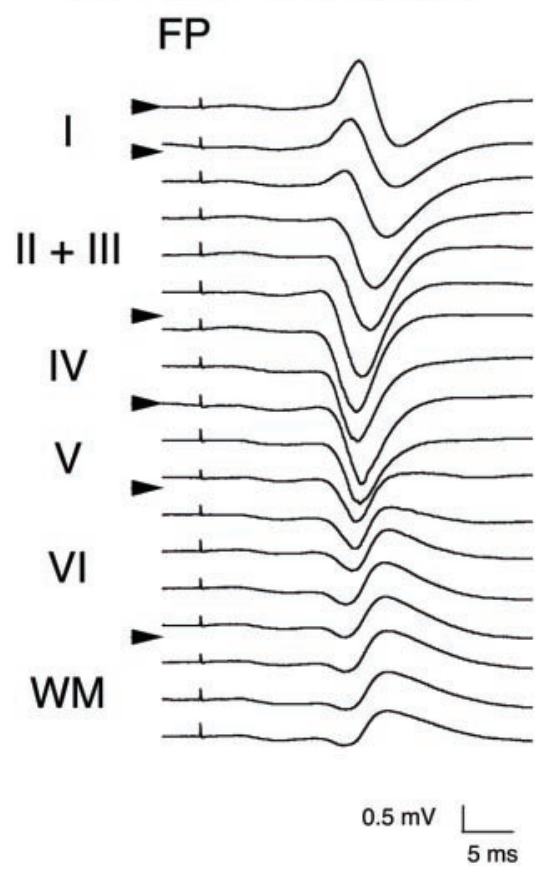

\section{CSD}

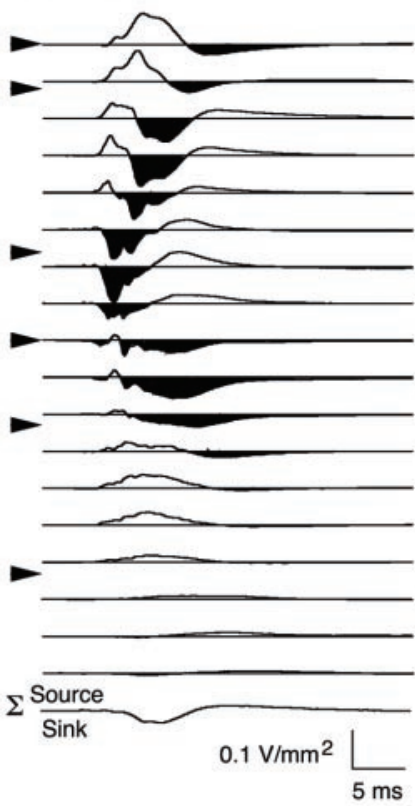

CSD Image

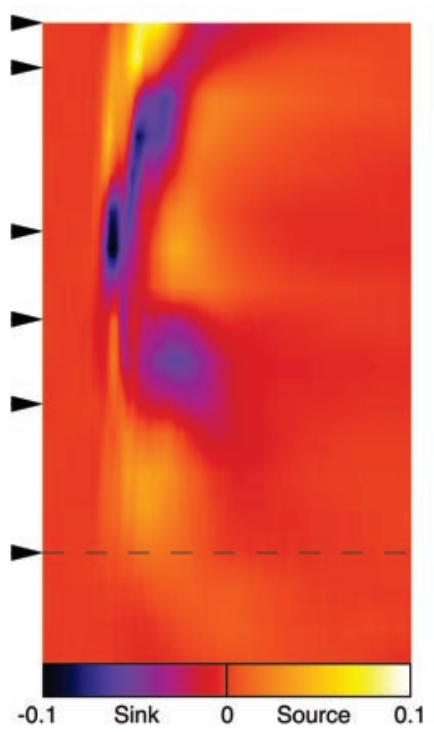

CSD Image

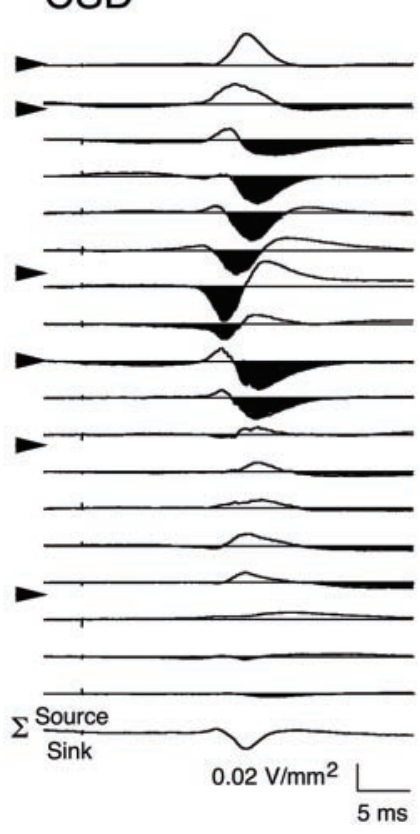

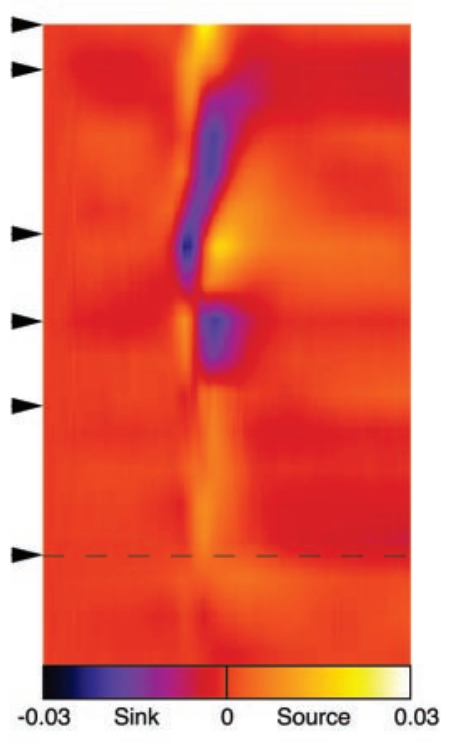

Figure 3. Electrical stimulation of the dLGN and photic stimulation of the retinas produce comparable laminar activation profiles in Oc1. The left column in $A$ and $B$ shows FPs recorded at different cortical depths in response to stimulation of dLGN and photic stimulation, respectively. Cortical layers and boundaries (arrowheads) are indicated at the left of each panel. The middle column of $A$ and $B$ presents CSD profiles obtained from FPs using a spatial differentiation grid of $200 \mu \mathrm{m}$. In this and subsequent figures, current sinks are downward and are shaded, and current sources are upward-going. Bottom trace $(\Sigma)$ is summation of all CSD traces across depth. The right column of $A$ and $B$ presents color image plots of CSD data. Cool colors (purple and blue) represent current sinks, and hot colors (yellow and white) represent current sources; orange is approximately zero. Color scale has been interpolated across depth (Aizenman et al., 1996). Dashed line indicates border of layer VI with white matter $(W M)$.

synaptic currents (sinks) in the middle layers may be obscured in these cases by the passive outward current sources generated at the same time at these depths.

Table 1 provides a summary of average changes in the ampli- tude and latency of current sinks in layers II-IV after LTP induction $(n=7)$. The amplitude of current sinks was increased in all layers, with statistically significant increases $(p<0.05)$ occurring in the superficial layers. Although no statistically sig- 
Table 1. Effects of LTP induction on amplitude and latency of current sinks in Oc1

\begin{tabular}{|c|c|c|c|c|c|c|}
\hline \multirow[b]{2}{*}{ Layer $^{a}$} & \multicolumn{2}{|c|}{ Amplitude $\left(\mathrm{V} / \mathrm{mm}^{2}\right)$} & \multicolumn{2}{|c|}{ Latency to sink onset (msec) } & \multicolumn{2}{|c|}{ Latency to sink maximum (msec) } \\
\hline & Pre-LTP & Post-LTP & Pre-LTP & Post-LTP & Pre-LTP & Post-LTP \\
\hline \multicolumn{7}{|l|}{ II } \\
\hline$(200-300 \mu \mathrm{m})$ & $0.15( \pm 0.04)$ & $0.32( \pm 0.12)^{*}$ & $5.63( \pm 0.81)$ & $6.56( \pm 0.83)$ & $8.32( \pm 0.87)$ & $10.06( \pm 0.80)$ \\
\hline III super & & & & & & \\
\hline$(300-500 \mu \mathrm{m})$ & $0.20( \pm 0.05)$ & $0.42( \pm 0.16)^{*}$ & $3.82( \pm 0.70)$ & $4.99( \pm 0.50)$ & $5.70( \pm 0.73)$ & $7.13( \pm 0.61)$ \\
\hline III deep & & & & & & \\
\hline$(500-600 \mu \mathrm{m})$ & $0.14( \pm 0.04)$ & $0.28( \pm 0.10)^{*}$ & $3.04( \pm 0.27)$ & $2.64( \pm 0.32)$ & $4.47( \pm 0.62)$ & $4.65( \pm 0.51)$ \\
\hline IV & & & & & & \\
\hline$(600-800 \mu \mathrm{m})$ & $0.19( \pm 0.08)$ & $0.26( \pm 0.09)$ & $1.78( \pm 0.20)$ & $1.73( \pm 0.13)$ & $2.28( \pm 0.18)$ & $2.66( \pm 0.21)$ \\
\hline
\end{tabular}

${ }^{a}$ Values in parentheses indicate cortical depth. ${ }^{*} p<0.05$.

\section{Before TBS}

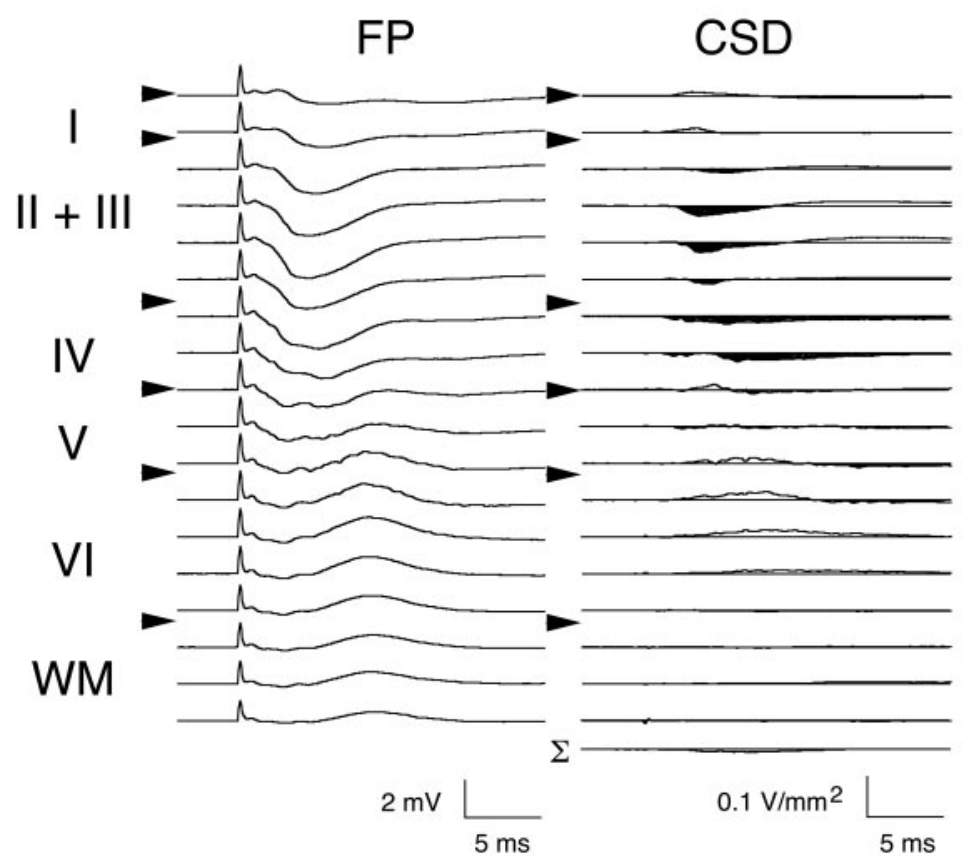

After TBS

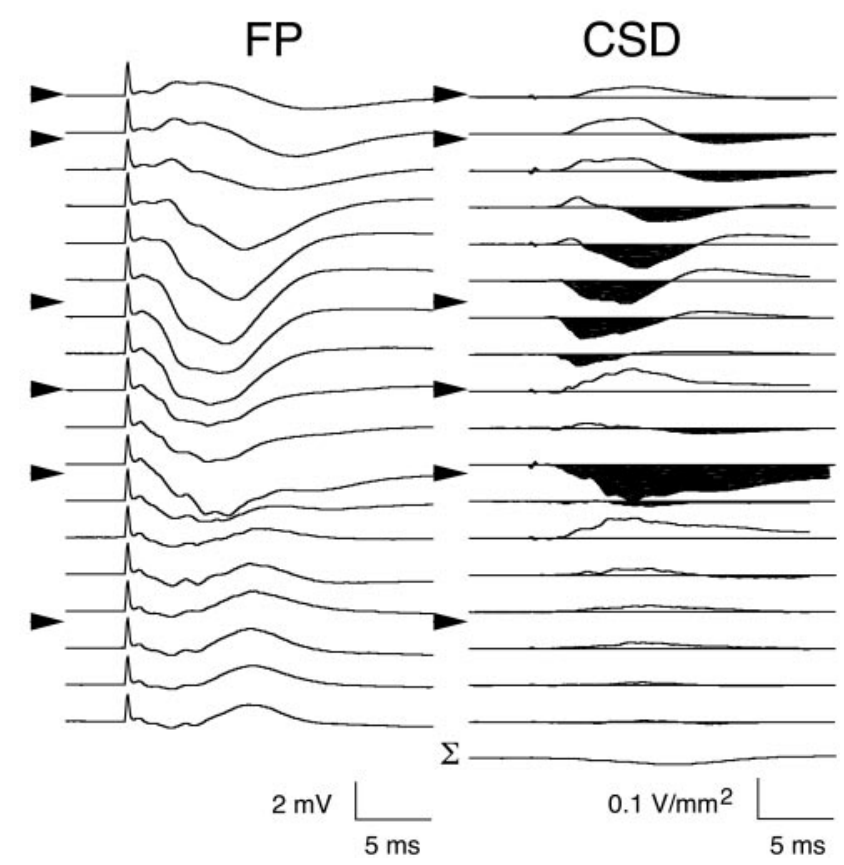

Figure 4. LTP in Oc1 in vivo is accompanied by an increase in granular and supragranular current sinks. First and third columns are FPs recorded at different cortical depths in response to dLGN stimulation before and after TBS, respectively. Note the increase in FP amplitude through layers I-IV after TBS. CSD profiles obtained from FPs are presented in columns two and four. Note the increase in current sink amplitude in thalamorecipient (layer IV and deep III) and supragranular (layer II/III) cell layers after LTP induction.

nificant differences in sink latency (onset and peak) was observed after TBS, there was a tendency for the sink maximum to shift to slightly longer latencies after LTP, and this was most pronounced in the most superficial layers.

\section{Increased expression of the immediate early gene zif- 268 after LTP}

In addition to terminating on neurons that reside in layers IV and deep III, the thalamocortical projection also synapses on dendrites that traverse these layers (e.g., layer V apical dendrites; (Peters and Feldman, 1977; Schober and Winkelmann, 1977; White, 1979). Although CSD analysis indicates the laminar location of changes in net synaptic currents, this technique does not allow for the determination of the target neurons that have recently undergone LTP. Therefore, to further study the locus of
TBS-induced changes in synaptic strength in our preparation, we performed immunohistochemical analysis for the IEG zif-268. Of a number of IEGs tested (e.g., c-jun, Jun-B, Jun-D, c-Fos), zif-268 (a.k.a. Krox-24, Egr-1, and NGFI-A) expression shows the strongest correlation with both the induction and maintenance of LTP in the hippocampus (Abraham et al., 1991, 1993; Demmer et al., 1993). Stimulation frequencies or intensities that fail to elicit LTP typically are not accompanied by an IEG response (Cole et al., 1989; Dragunow et al., 1989). Moreover, activity-dependent increases in zif-268 mRNA and protein, in both hippocampus and visual cortex, have been shown to depend on NMDA receptoractivation (Cole et al., 1989; Wisden et al., 1990; Worley et al., 1991, 1993). Given the strong relationship between zif-268 expression and activity-dependent increases in synaptic strength, we 

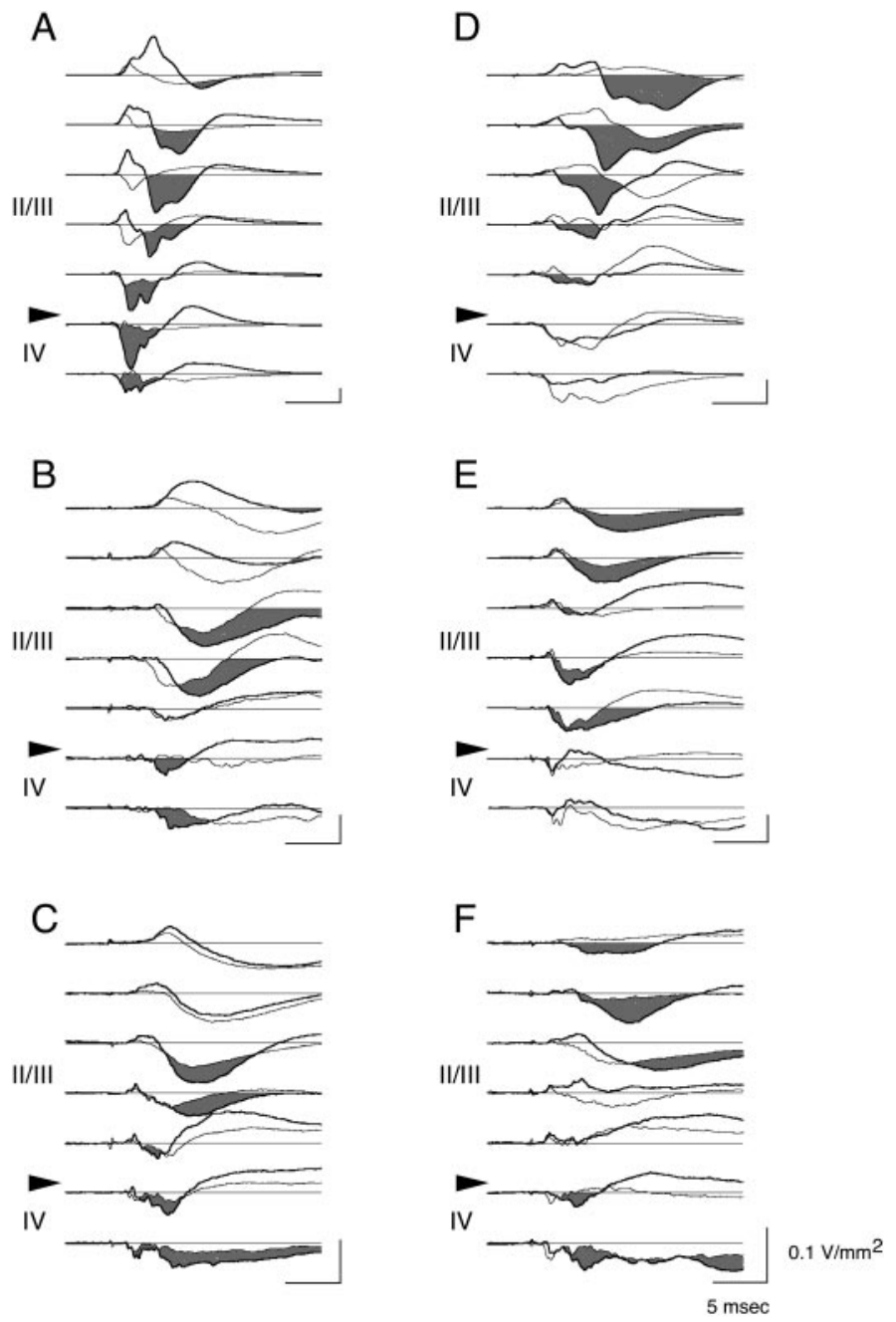

Figure 5. Comparison of current sinks located in granular and supragranular cell layers before and after LTP induction. Overlay plots of CSD traces obtained from granular (IV) and supragranular (II/III) cell layers before (thin traces) and after (thick traces) induction of LTP in six animals. Note increase in current sink amplitude (shaded area) in supragranular cell layers after LTP in all animals. Note also in $A-C$ the increase in layer IV current sinks after LTP induction.

elected to use zif-268 as a marker to gain further insight into the laminar locus of LTP in Oc1 in vivo.

Animals had stimulating and recording electrodes positioned in each hemisphere. After a $30 \mathrm{~min}$ baseline period in which alternating pulses were applied to the dLGN of each hemisphere, TBS was then applied to one hemisphere. Alternating stimulation was then resumed for $1 \mathrm{hr}$ before killing. Tissue obtained from Oc1 of both hemispheres was immunostained to allow for a within animal control for TBS-induced changes in zif-268 expression. Figure $6 \mathrm{~A}$ presents the electrophysiological data for these animals. Note that stable potentiation of the FP amplitude $(133.8 \pm 6.2 \%$ of baseline; $p<0.01$; filled circles) was observed in Oc1 of the hemisphere receiving tetanization, whereas no change in FP amplitude was observed in Oc1 of the control hemisphere (96.6 \pm $11.1 \%$ of baseline; $p>0.7$; open circles).

Photomicrographs of zif-268 immunolabeling in Oc1 of one animal are shown in Figure $6 B$. In Oc1 ipsilateral to the dLGN receiving only baseline stimulation, scattered zif-268-immunopositive neurons are observed in layers II, III, IV and, most prominently, in layer VI. Immunostaining is absent in layer I, and only faint, sparse staining is observed in layer V. In comparison, there is a marked increase in the number of zif-268-positive neurons in Oc1 of the hemisphere receiving TBS. The increase is confined mainly to layers II-IV; little change is observed in layers V, VI, or I.

Quantitative analysis of the number of zif-268-immunopositive neurons in layers II, III, IV, and VI was performed for control and tetanized cortices (because of the scarcity of labeling in layers I and $\mathrm{V}$, these regions were excluded from this analysis). Compared with control Oc1, a significant increase ( $p<0.05$; paired $t$ test) in the number of zif-268-immunopositive neurons was found in layers II/III $(635 \pm 133 \%)$ and IV $(243 \pm 38 \%)$ of Oc1 that had undergone LTP induction (Fig. 6C). An increase in the

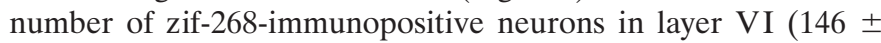
$17 \%$ ) was also found, although this increase did not reach statistical significance ( $p>0.2$; paired $t$ test).

These immunohistochemical results demonstrate that induction of LTP is accompanied by a marked increase in zif-268 immunoreactivity in Oc1, particularly in neurons located within granular and supragranular layers. This increase is seen over a wide extent of Oc1 of the hemisphere receiving tetanization, apparently because of the fact that stimulation near the anterior pole of the dLGN activates a large proportion of optic radiation fibers (Hughes, 1977; Molnar et al., 1998). These findings are in agreement with previous observations in hippocampus demonstrating that NMDA receptor-dependent synaptic strengthening is accompanied by an increase in zif-268 expression (Abraham et al., 1991; Worley et al., 1993; Barnes et al., 1994). Taken together with the CSD analysis, the data suggest that layers II-IV are sites of synaptic modification after TBS of the dLGN.

\section{Effect of LTP on cortical responses to visual stimulation}

We next investigated how LTP alters cortical responses to visual stimulation. Our first approach was simply to monitor flashevoked potentials (FEPs) in visual cortex immediately before and $1 \mathrm{hr}$ after TBS of the dLGN. The change in dLGN-evoked FPs in these animals $(n=5)$ measured 60 min after TBS was $133.9 \pm$ $8.4 \%$ of baseline (Fig. $7 A)(p<0.05$, paired $t$ test), and there was a corresponding increase in the FEPs $(120.8 \pm 5.2 \%$ of baseline; $p<0.05$; paired $t$ test). In two of these animals CSD analysis was performed on FP profiles obtained before and after application of TBS. In both cases, clear increases in the amplitudes of both dLGN- and flash-evoked current sinks are observed in granular and supragranular cell layers after TBS (Fig. 7B). Thus, LTP in the geniculocortical pathway potentiates sensory responses in the visual cortex.

Another way to assess the functional consequences of LTP in the geniculocortical pathway is to monitor VEPs using patternreversing sinusoidal gratings. VEPs are a useful indicator of visual function and have been used to monitor the strength of thalamocortical synaptic transmission (Fagiolini et al., 1994; Pizzorusso et al., 1997; Guire et al., 1999). Therefore, in a final series of experiments, we monitored VEPs in response to high-contrast gratings presented at various spatial frequencies before and after inducing LTP.

Six animals were prepared with stimulating and recording electrodes positioned in the dLGN and Oc1 of each hemisphere. VEPs were collected immediately before and $\geq 30 \mathrm{~min}$ after delivering TBS to the dLGN on one side; the simultaneously recorded VEPs in the contralateral hemisphere controlled for 

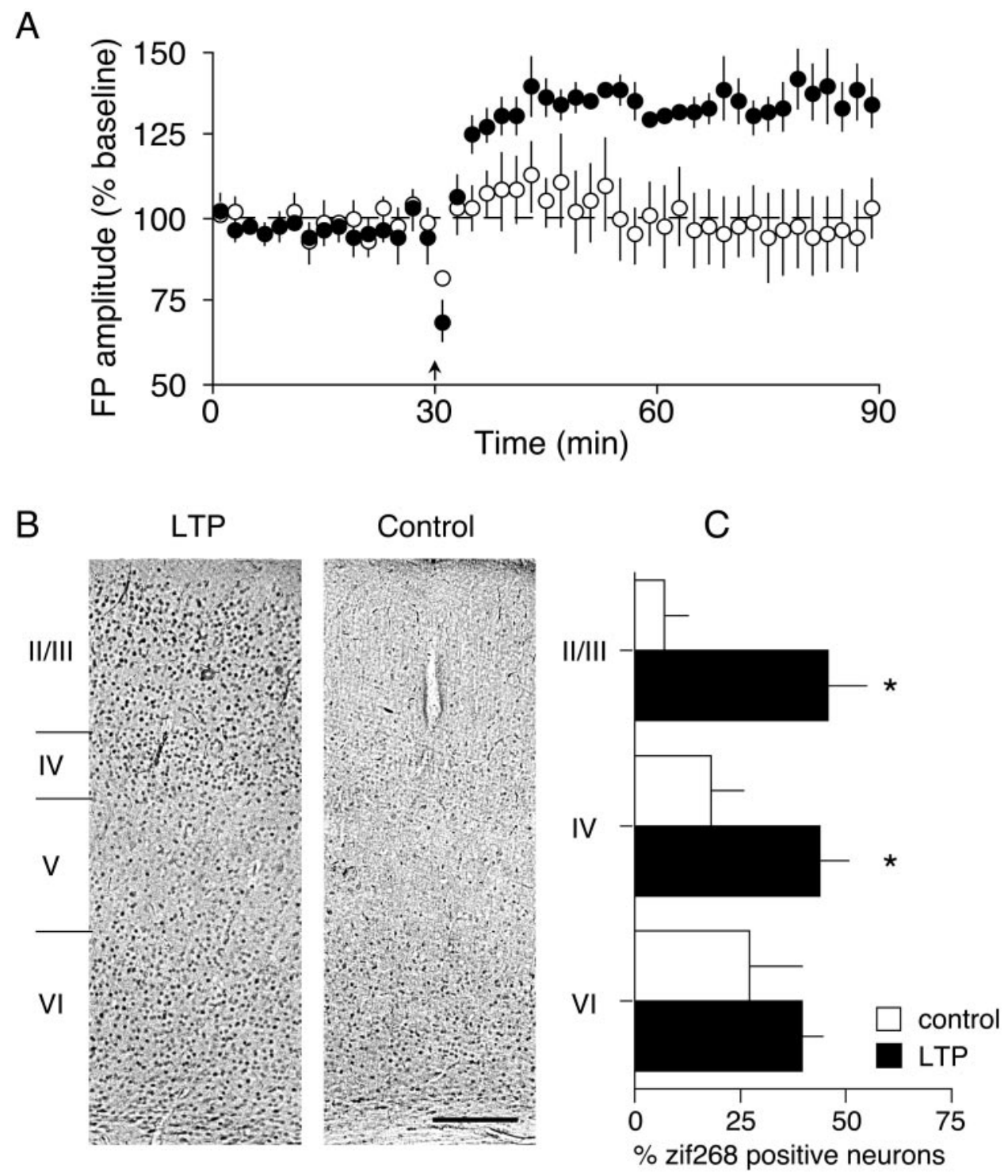

Figure 6. LTP induction in Oc1 in vivo is accompanied by an increase in zif-268 immunoreactivity. $A$, Electrophysiological data from animals used for zif-268 immunohistochemistry. After a $30 \mathrm{~min}$ baseline recording period, TBS was applied to the dLGN of one hemisphere (closed circles), and baseline recording resumed for $1 \mathrm{hr}$ before preparation for zif268 immunohistochemistry. Whereas stable LTP is observed in Oc1 of the tetanized hemisphere, no change in FP amplitude is observed in control Oc1 (open circles). $B, \quad$ Bright-field photomicrographs demonstrating laminar distribution of zif268 immunoreactivity in LTP (left panel) and control (right panel) Oc1 of one animal. Scale bar, $200 \mu \mathrm{m}$. C, Histogram demonstrating number of zif-268-immunopositive neurons in layers II/III, IV, and VI of control and LTP Oc1. Asterisk indicates significant increase compared with control Oc1 $(p<0.05$; paired $t$ test $)$.

variations caused by changes in the EEG. Although we did not perform a CSD analysis, previous studies suggest that the prominent positive VEP recorded at the surface reflects current flowing from sources in the most superficial layers because of deep layer III sinks (Schroeder et al., 1991). Figure $8 A$ presents the VEPs obtained before and after LTP induction in one animal. In this example, a clear increase in VEP amplitude is observed across a range $\left(0.05-0.7 \mathrm{cycles}^{\circ}\right)$ of stimulus spatial frequencies after application of TBS.

To analyze the group data, the VEPs from each hemisphere were normalized to the maximum response elicited by the lowest spatial frequency grating $\left(0.05\right.$ cycles $\left./{ }^{\circ}\right)$ before TBS and averaged across animals (Fig. 8B). A two-way ANOVA performed on the data from each hemisphere revealed, as expected, a significant main effect of spatial frequency. In addition, in the tetanized hemisphere, VEP amplitude was significantly increased after TBS across a range $\left(0.05-0.4\right.$ cycles $\left./^{\circ}\right)$ of stimulus spatial frequencies $\left(\right.$ ANOVA; $\left.F_{(1,50)}=6.56 ; p<0.02\right)$.

\section{DISCUSSION}

We have shown that tetanic stimulation of the dLGN reliably potentiates excitatory synaptic transmission of both electrically and visually evoked activity in the geniculocortical pathway. The data suggest a greater potential for modification of adult visual cortex than previously appreciated.

\section{Interpretation of changes in cortical FPs}

TBS of the dLGN potentiates the extracellular response recorded at the dural surface to electrical stimulation of the geniculocortical pathway. One-dimensional CSD analysis was performed to investigate the meaning of this change. This analysis revealed a spatiotemporal pattern of sources and sinks evoked by dLGN stimulation corresponding closely with that evoked by photic stimulation and consistent with a number of previous studies. The shortest latency sink appears in layer IV/deep III, followed by a large-amplitude sink in superficial layer II/III and a long duration sink in layer V. This pattern of activation is consistent with the notion that dLGN stimulation activates thalamocortical input to layer IV/deep III, followed by disynaptic and polysynaptic activation of layers II-III and V, respectively, with a negligible contribution of antidromic cortical activation. The negative-going FP recorded at the surface appears to reflect mainly the layer II-III current sink. Thus, it is not surprising that this superficial layer sink is also reliably potentiated by TBS of the dLGN. In most 
A
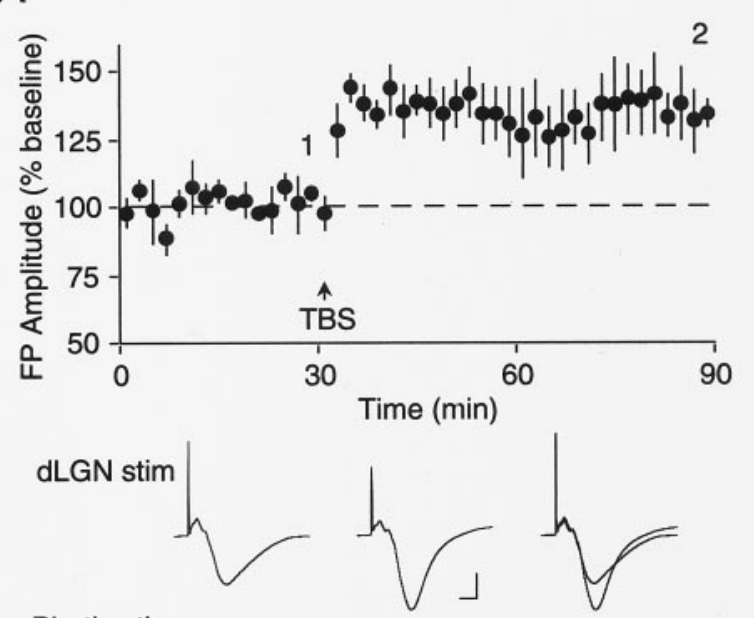

Photic stim

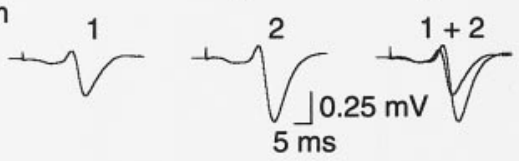

B

\section{dLGN stimulation photic stimulation}
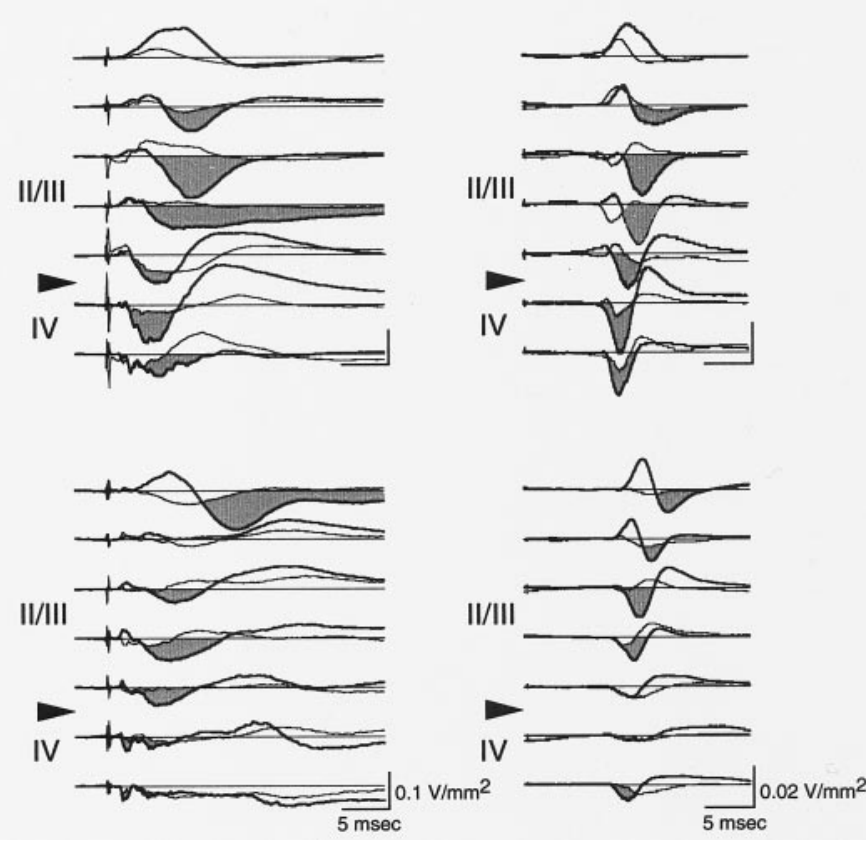

Figure 7. LTP in Oc1 in vivo is accompanied by an enhancement of the cortical response to photic stimulation. $A$, TBS application to the dLGN results in LTP of FPs elicited by electrical stimulation of the dLGN and photic stimulation of the retinas. Data are plotted for dLGN-evoked FPs. Traces are from one animal demonstrating change in the dLGN- and photic-evoked FPs at times indicated by the numbers. B, TBS-induced increases in synaptic strength are accompanied by comparable increases in dLGN- and photic-evoked current sinks. CSD profiles obtained from granular (IV) and supragranular (II/III) cell layers of two animals before (thin traces) and after (thick traces) LTP induction. Note that after LTP induction an increase in current sink amplitude is observed in the thalamorecipient and supragranular cell layers. Note also in each example the comparable laminar pattern of current sink changes in response to both modes of stimulation. cases (four of seven), the short-latency sink in layer IV and the layer $\mathrm{V}$ sink were also increased after TBS.

The picture provided by this method is incomplete, however, because it reveals only long current loops that flow along a line running normal to the cortical surface. The practical consequence is that activation of layer IV cells, with short dendritic arbors, is grossly underestimated using the CSD method. Thus, whereas CSD analysis is useful for studying synaptic currents in superficial layer apical dendrites, an absence of sinks at other cortical depths does not necessarily signify the absence of synaptic activation or synaptic change. Indeed, it seems likely based on the analysis of zif-268 induction that synapses on layer IV neurons are affected to a greater extent than what is suggested by CSD analysis.

Although enhanced current sinks in layers II-V signify greater net inward synaptic currents, the basis for this change is likely to vary depending on the layer. Potentiation of the current sinks in layers IV and deep III likely reflects modification of the strength of monosynaptic thalamocortical connections. Interpretation becomes less clear for disynaptic and polysynaptic current sinks in extragranular layers. Potentiation of geniculocortical synapses would be expected to lead to recruitment of a larger population of layer IV/deep III neurons spiking in response to pulse stimulation of the dLGN. This effect alone would increase disynaptic and polysynaptic current sinks in superficial and deep layers. In the case of layer II/III, however, we suggest that intracortical synapses are also potentiated, for two reasons. First, it is well established that layer II/III is a site of robust synaptic plasticity in adult visual cortex (Kirkwood and Bear, 1984). Second, we observed clear examples of LTP of layer II/III sinks without any change in layer IV/deep III. Layer V changes, on the other hand, may be attributable entirely to recruitment of more presynaptic neurons in layer III.

\section{Comparison with previous studies}

In general, our findings are in excellent agreement with numerous studies of LTP in slices of neocortex. For example, in slices of rat visual cortex Kirkwood and Bear (1994) found that LTP of synaptic responses in layer III could be readily elicited by TBS. As in the present study, LTP induced by TBS in vitro was NMDA receptor-dependent, saturable, and long lasting. One interesting difference is that LTP elicited by stimulation of the white matter declined sharply with age, whereas we had no difficulty eliciting LTP by dLGN stimulation in adults in vivo. (This difference will be discussed below.) It is important to note, however, that by stimulating layer IV of slices instead of white matter, LTP could be readily observed in layer III at all ages. Thus, the slice data are consistent with the conclusion that the mechanisms that support NMDA receptor-dependent LTP persist in the neocortex well into adulthood.

There are fewer previous studies of LTP in the neocortex in vivo. A series of pioneering experiments (Tsumoto and Suda, 1979; Komatsu et al., 1988) showed that prolonged low-frequency $(2 \mathrm{~Hz}$ ) stimulation of the dLGN in kittens, but not cats, triggers a slow onset potentiation of the FP evoked in visual cortex. These findings are obviously different from ours in terms of the conditions for induction, age dependence, and time course of the effect. This type of plasticity also likely differs at the mechanistic level. When the same phenomenon was studied in slices of kitten visual cortex, it was discovered that the effect was not dependent on NMDA receptors (Komatsu et al., 1991; Komatsu and Iwakiri, 1992). Presumably the differences stem from variations in exper- 


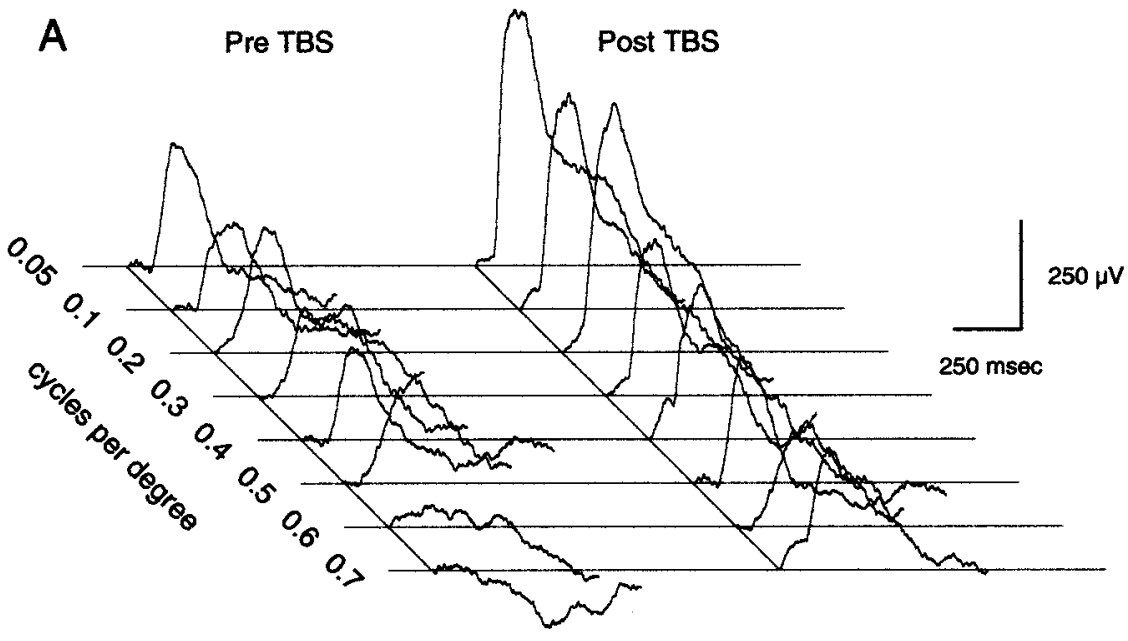

B

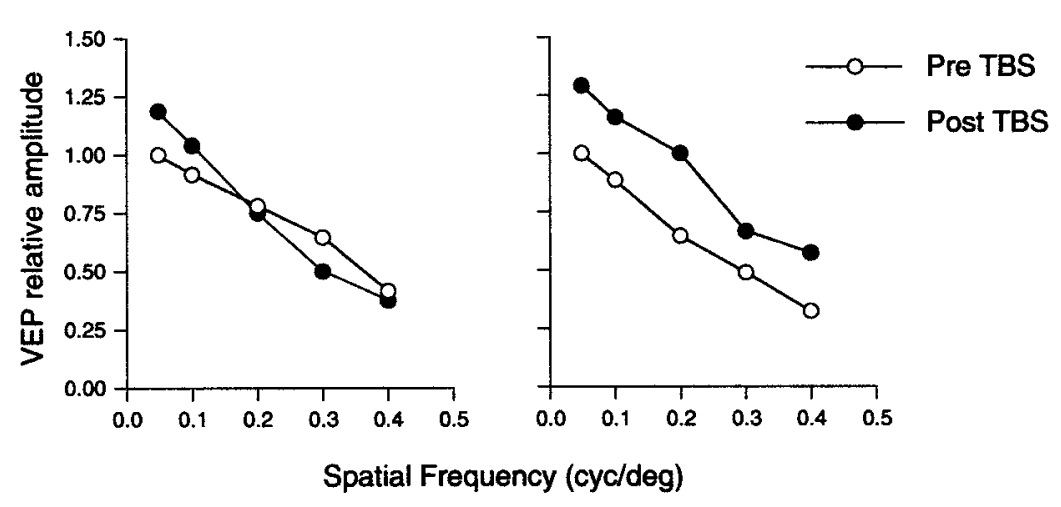

Figure 8. LTP induction in Oc1 in vivo results in an enhancement of pattern-evoked field potentials. $A$, VEPs obtained from one animal before (Pre TBS) and after (Post TBS) application of TBS to the dLGN. Note the increase in VEP amplitude across a range of spatial frequencies $\left(0.05-0.7\right.$ cycles $\left./{ }^{\circ}\right)$ indicated at left for each pair of traces after TBS. B, Summary of TBS-induced changes in VEP amplitude. Data obtained from control Oc1 (left panel) and Oc1 in which LTP was induced (right panel). Data for each hemisphere are normalized to the VEP amplitude measured using a 0.05 cycles $/{ }^{\circ}$ stimulus during pre-TBS recording period. imental conditions, obviously including the species. However, studies of hippocampal LTP provide ample precedent for multiple, mechanistically distinct forms of LTP expressed at different synapses in the same parts of the cerebral cortex. Thus, our demonstration of NMDAR-dependent LTP in adult rat visual cortex does not exclude the possibility that other mechanisms of synaptic potentiation also exist in rat visual cortex (Aroniadou and Teyler, 1992).

The most comparable previous study was performed in the adult rat somatosensory cortex by Lee and Ebner (1992). They monitored the strength of thalamocortical transmission by recording the spikes generated by layer IV neurons in response to stimulation of a single vibrissa. This activity could be persistently increased by tetanic stimulation of the ventrobasal thalamus, as well as by repetitive stimulation of the vibrissa if thalamic inhibition was reduced pharmacologically. Although involvement of NMDA receptors in this modification was not investigated, these results are consistent with the conclusion that thalamocortical synapses can support LTP in the adult brain.

In addition to these and related studies using thalamic stimulation to induce LTP in neocortex (Iriki et al., 1989, 1991), there are numerous reports of response enhancement in individual cortical neurons after cellular conditioning protocols (Frégnac et al., 1988, 1992; Greuel et al., 1988; Cruikshank and Weinberger, 1996; Eysel et al., 1998; McLean and Palmer, 1998). In all cases, pairing presynaptic stimulation with strong postsynaptic responses-conditions favorable for the induction of NMDA receptordependent LTP_enhanced cortical responsiveness to the paired stimulus. This plasticity is readily induced in adults (McLean and Palmer, 1998) and has been observed in short-latency sensory responses, suggesting modification of monosynaptic thalamocortical input (Cahusac, 1995).

\section{Significance}

We believe the current findings are significant for at least two reasons. One concerns the issue of developmental regulation of synaptic plasticity in sensory neocortex; the other concerns the potential to modify with LTP cortical responses to sensory stimulation.

One of the defining features of experience-dependent plasticity in visual cortex is the critical period-the time in early postnatal life when primary sensory cortex is most modifiable. Because the mechanisms of LTP and LTD are thought to contribute to experience-dependent modifications of the cortex, developmental changes in LTP and LTD have been studied in the hope of gaining insight into why plasticity diminishes with age. In slice preparations, it is well documented that LTP evoked with subcortical electrical stimulation declines in sensory neocortex with a time course similar to the naturally occurring critical periods (Artola and Singer, 1987; Kato et al., 1991; Crair and Malenka, 1995; Kirkwood et al., 1995; Barth and Malenka, 2001). Two hypotheses have been proposed to account for the LTP critical period. One suggests a developmental downregulation of molecules required to support LTP of thalamocortical synapses (Crair and Malenka, 1995; Barth and Malenka, 2001); the second suggests a developmental upregulation of cortical inhibition, impos- 
ing constraints on the stimulation requirements for LTP induction (Kato et al., 1991; Kirkwood and Bear, 1994; Kirkwood et al., 1995; Huang et al., 1999). Our data favor the second hypothesis because they show that the constraints on adult LTP can be overcome with thalamic stimulation in vivo. The precise reasons for our success in vivo are unknown, but possibilities include the synchronous activation of a large extent of visual cortex with TBS of the dLGN or the presence of neuromodulators in the milieu in vivo that are absent or reduced in slices.

A striking consequence of LTP in vivo is an altered cortical response to visual stimulation. The functional consequences of this modification need to be investigated in future studies, e.g., by studying changes in receptive fields and visually guided behavior. However, it is interesting that LTP was found to increase VEP amplitude across a range of spatial frequencies. If this change translates into an increased signal-to-noise ratio, then it is possible that the induction of LTP may alter the performance of the visual system. One lasting consequence of visual deprivation in early life is transmission failure at geniculocortical synapses and poor visual performance through the deprived eye. Our data suggest that mechanisms are available in the adult visual cortex to reverse this deprivation-induced amblyopia.

\section{REFERENCES}

Abraham W, Mason S (1988) Effects of NMDA receptor antagonists CPP and MK801 on hippocampal field potentials and long-term potentiation in urethane anesthetized rats. Brain Res 462:40-46.

Abraham WC, Dragunow M, Tate WP (1991) The role of immediate early genes in the stabilization of long-term potentiation. Mol Neurobiol 5:297-314.

Abraham WC, Mason SE, Demmer J, Williams JM, Richardson CL, Tate WP, Lawlor PA, Dragunow M (1993) Correlations between immediate early gene induction and the persistence of long-term potentiation. Neuroscience 56:717-727.

Aizenman CD, Kirkwood A, Bear MF (1996) Current source density analysis of evoked responses in visual cortex in vitro: implications for the regulation of long-term potentiation. Cereb Cortex 16:751-758.

Aroniadou VA, Teyler TJ (1992) Induction of NMDA receptorindependent long-term potentiation (LTP) in visual cortex of adult rats. Brain Res 584:169-173.

Artola A, Singer W (1987) Long-term potentiation and NMDA receptors in rat visual cortex. Nature 330:649-652.

Barnes CA, Jung MW, McNaughton BL, Korol DL, Andreasson K, Worley PF (1994) LTP saturation and spatial learning disruption: effects of task variables and saturation levels. J Neurosci 14:5793-5806.

Barth AL, Malenka RC (2001) NMDAR EPSC kinetics do not regulate the critical period for LTP at thalamocortical synapses. Nat Neurosci 4:235-236.

Bear MF (1996) A synaptic basis for memory storage in the cerebral cortex. Proc Natl Acad Sci USA 93:13453-13459.

Bear MF, Cooper LN, Ebner FF (1987) A physiological basis for a theory of synaptic modification. Science 237:42-48.

Bourassa J, Deschenes M (1995) Corticothalamic projections from the primary visual cortex in rats: a single fiber study using biocytin as an anterograde tracer. Neuroscience 66:253-263.

Brankack J, Schober W, Klingberg F (1990) Different laminar distribution of flash evoked potentials in cortical areas 17 and $18 \mathrm{~b}$ of freely moving rats. J Hirnforsch 31:525-533.

Buonomano DV, Merzenich MM (1998) Cortical plasticity: from synapses to maps. Annu Rev Neurosci 21:149-186.

Burkhalter A (1989) Intrinsic connections of rat primary visual cortex: laminar organization of axonal projections. J Comp Neurol 279:171-186.

Cahusac PM (1995) Synaptic plasticity induced in single neurones of the primary somatosensory cortex in vivo. Exp Brain Res 107:241-253.

Chen WR, Lee S, Kato K, Spencer DD, Shepherd GM, Williamson A (1996) Long-term modifications of synaptic efficacy in the human inferior and middle temporal cortex. Proc Natl Acad Sci USA 93:8011-8015.

Cole AJ, Saffen DW, Baraban JM, Worley PF (1989) Rapid increase of an immediate early gene messenger RNA in hippocampal neurons by synaptic NMDA receptor activation. Nature 340:474-476.

Crair MC, Malenka RC (1995) A critical period for long-term potentiation at thalamocortical synapses. Nature 375:325-328.

Cruikshank SJ, Weinberger NM (1996) Receptive-field plasticity in the adult auditory cortex induced by Hebbian covariance. J Neurosci 16:861-875.

Demmer J, Dragunow M, Lawlor PA, Mason SE, Leah JD, Abraham WC, Tate WP (1993) Differential expression of immediate early genes after hippocampal long-term potentiation in awake rats. Brain Res Mol Brain Res 17:279-286.

Dragunow D, Abraham W, Goulding M, Mason S, Robertson H, Faull R (1989) Long-term potentiation and the induction of c-fos mRNA and proteins in the dentate gyrus of unanesthetized rats. Neurosci Lett 101:274-280.

Eysel UT, Eyding D, Schweigart G (1998) Repetitive optical stimulation elicits fast receptive field changes in mature visual cortex. NeuroReport 9:949-954.

Fagiolini M, Pizzorusso T, Berardi N, Domenici L, Maffei L (1994) Functional postnatal development of the rat primary visual cortex and the role of visual experience: dark rearing and monocular deprivation. Vision Res 34:709-720.

Ferster D (1990) X- and Y-mediated current sources in areas 17 and 18 of cat visual cortex. Vis Neurosci 4:135-145.

Ferster D, Lindstrom S (1983) An intracellular analysis of geniculocortical connectivity in area 17 of the cat. J Physiol (Lond) 342:181-215.

Freeman JA, Nicholson C (1975) Experimental optimization of current source-density technique for anuran cerebellum. J Neurophysiol 38:369-382.

Frégnac Y, Shulz D (1994) Models of synaptic plasticity and cellular analogs of learning in the developing and adult vertebrate visual cortex. In: Advances in neural and behavioral development (Casagrande VA, Shinkman PG, eds), pp 149-252. Norwood, NJ: Ablex.

Frégnac Y, Shultz D, Thorpe S, Bienenstock E (1988) A cellular analogue of visual cortical plasticity. Nature 333:367-370.

Frégnac Y, Shulz D, Thorpe S, Bienenstock E (1992) Cellular analogs of visual cortical epigenesis. I. Plasticity of orientation selectivity. J Neurosci 12:1280-1300.

Greuel JM, Luhmann HJ, Singer W (1988) Persistent changes of singlecell responses in kitten striate cortex produced by pairing sensory stimulation with ionophoretic application of neurotransmitters and neuromodulators. In: Cellular mechanisms of conditioning and behavioral plasticity (Woody CD, Alkon DL, McGaugh JL, eds), pp 425-436. New York: Plemun.

Guire ES, Lickey ME, Gordon B (1999) Critical period for the monocular deprivation effect in rats: assessment with sweep visually evoked potentials. J Neurophysiol 81:121-128.

Heynen AJ, Abraham WC, Bear MF (1996) Bidirectional modification of CA1 synapses in the adult hippocampus in vivo. Nature 381:163-166.

Huang ZJ, Kirkwood A, Pizzorusso T, Porciatti V, Morales B, Bear MF, Maffei L, Tonegawa S (1999) BDNF regulates the maturation of inhibition and the critical period of plasticity in mouse visual cortex. Cell 98:739-755.

Hughes HC (1977) Anatomical and neurobehavioral investigations concerning the thalamo-cortical organization of the rat's visual system. J Comp Neurol 175:311-336.

Iriki A, Pavlides C, Keller A, Asanuma H (1989) Long-term potentiation in the motor cortex. Science 245:1385-1387.

Iriki A, Pavlides C, Keller A, Asanuma H (1991) Long-term potentiation of thalamic input to the motor cortex induced by coactivation of thalamocortical and corticocortical afferents. J Neurophysiol 65:1435-1441

Kato N, Artola A, Singer W (1991) Developmental changes in the susceptibility to long-term potentiation of neurones in rat visual cortex slices. Dev Brain Res 60:43-50.

Kenan-Vaknin G, Teyler TJ (1994) Laminar pattern of synaptic activity in rat primary visual cortex: comparison of in vivo and in vitro studies employing the current source density analysis. Brain Res 635:37-48.

Kenan-Vaknin G, Malach R, Segal M (1992) Excitatory inputs to layer $\mathrm{V}$ pyramidal cells of rat primary visual cortex revealed by acetylcholine activation. Brain Res 574:147-156.

Kirkwood A, Bear MF (1994) Hebbian synapses in visual cortex. J Neurosci 14:1634-1645.

Kirkwood A, Dudek SM, Gold JT, Aizenman CD, Bear MF (1993) Common forms of synaptic plasticity in the hippocampus and neocortex in vitro. Science 260:1518-1521.

Kirkwood A, Lee H-K, Bear MF (1995) Co-regulation of long-term potentiation and experience-dependent plasticity in visual cortex by age and experience. Nature 375:328-331.

Komatsu Y, Iwakiri M (1992) Low-threshold $\mathrm{Ca}^{2+}$ channels mediate induction of long-term potentiation in kitten visual cortex. J Neurophysiol 67:401-410.

Komatsu Y, Fujii K, Maeda J, Sakaguchi H, Toyama K (1988) Longterm potentiation of synaptic transmission in kitten visual cortex. J Neurophysiol 59:124-141.

Komatsu Y, Nakajima S, Toyama K (1991) Induction of long-term potentiation without the participation of $N$-methyl-D-aspartate receptors in kitten visual cortex. J Neurophysiol 65:20-32.

Lee SM, Ebner FF (1992) Induction of high frequency activity in the 
somatosensory thalamus of rats in vivo results in long-term potentiation of responses in SI cortex. Exp Brain Res 90:253-261.

Malenka RC, Nicoll RA (1999) Long-term potentiation-a decade of progress? Science 285:1870-1874.

McLean J, Palmer LA (1998) Plasticity of neuronal response properties in adult cat striate cortex. Vis Neurosci 15:177-196.

Mitzdorf U (1985) Current source-density method and application in cat cerebral cortex: Investigation of evoked potentials and EEG phenomena. Physiol Rev 65:37-100.

Mitzdorf U, Singer W (1978) Prominent excitatory pathways in the cat visual cortex (A17 and A18): a current source density analysis of electrically evoked potentials. Exp Brain Res 33:371-394.

Molnar Z, Adams R, Blakemore C (1998) Mechanisms underlying the early establishment of thalamocortical connections in the rat. J Neurosci 18:5723-5745.

Parnavelas JG, Sullivan K, Lieberman AR, Webster KE (1977) Neurons and their synaptic organization in the visual cortex of the rat. Electron microscopy of Golgi preparations. Cell Tissue Res 183:499-517.

Peters A, Feldman ML (1977) The projection of the lateral geniculate nucleus to area 17 of the rat cerebral cortex. IV. Terminations upon spiny dendrites. J Neurocytol 6:669-689.

Pizzorusso T, Fagiolini M, Porciatti V, Maffei L (1997) Temporal aspects of contrast visual evoked potentials in the pigmented rat: effect of dark rearing. Vision Res 37:389-395.

Rioult-Pedotti MS, Friedman D, Donoghue JP (2000) Learning-induced LTP in neocortex. Science 290:533-536.

Schmued LC, Swanson LW, Sawchenko PE (1982) Some fluorescent counterstains for neuroanatomical studies. J Histochem Cytochem 30:123-128.

Schober W, Winkelmann E (1977) [The geniculo-cortical projection in albino rats]. J Hirnforsch 18:1-20.

Schroeder CE, Tenke CE, Givre SJ, Arezzo JC, Vaughan HJ (1991) Striate cortical contribution to the surface-recorded pattern-reversal VEP in the alert monkey. Vision Res [Erratum (1991) 31:I] 31:1143-1157.
Singer W (1995) Development and plasticity of cortical processing architectures. Science 270:758-759.

Swadlow HA, Weyand TG (1981) Efferent systems of the rabbit visual cortex: laminar distribution of the cells of origin, axonal conduction velocities, and identification of axonal branches. J Comp Neurol 203:799-822.

Tamura H, Tsumoto T, Hata Y (1992) Activity-dependent potentiation and depression of visual cortical responses to optic nerve stimulation in kittens. J Neurophysiol 68:1603-1612.

Tsumoto T, Suda K (1979) Cross-depression: an electrophysiological manifestation of binocular competition in the developing visual cortex. Brain Res 168:190-194.

Tsumoto T, Suda K (1980) Three groups of cortico-geniculate neurons and their distribution in binocular and monocular segments of cat striate cortex. J Comp Neurol 193:223-236.

Vaknin G, DiScenna P, Teyler T (1988) A method for calculating current source density (CSD) analysis without resorting to recording sites outside the sampling volume. J Neurosci Methods 24:131-135.

Weinberger NM (1995) Dynamic regulation of receptive fields and maps in the adult sensory cortex. Annu Rev Neurosci 18:129-158.

White EL (1979) Thalamocortical synaptic relations: a review with emphasis on the projections of specific thalamic nuclei to the primary sensory areas of the neocortex. Brain Res 180:275-311.

Wisden W, Errington ML, Williams S, Dunnett SB, Waters C, Hitchcock D, Evan G, Bliss TV, Hunt SP (1990) Differential expression of immediate early genes in the hippocampus and spinal cord. Neuron 4:603-614.

Worley PF, Christy BA, Nakabeppu Y, Bhat RV, Cole AJ, Baraban JM (1991) Constitutive expression of zif268 in neocortex is regulated by synaptic activity. Proc Natl Acad Sci USA 88:5106-5110.

Worley PF, Bhat RV, Baraban JM, Erickson CA, McNaughton BL, Barnes CA (1993) Thresholds for synaptic activation of transcription factors in hippocampus: correlation with long-term enhancement. J Neurosci 13:4776-4786.

Zilles K (1985) The cortex of the rat. Berlin: Springer. 